\title{
La confidencialidad en la resolución del recurso especial en materia de contratación en el sector de la defensa y la seguridad pública y el Tribunal Administrativo Central de Recursos Contractuales
}

\author{
Martín Bassols Coma \\ Catedrático de Derecho Administrativo \\ martinbassolscoma@yahoo.es
}

Resumen

El objetivo de este estudio es el análisis de la Contratación publica en el sector de la Defensa y la Seguridad publica a efectos de las medidas que deben adoptar en sus resoluciones el Tribunal Administrativo Central de Recursos Contractuales o los Organismos autonómicos especializados de las Comunidades Autónomas en orden a la protección de la seguridad en la información de la documentación contractual y la confidencialidad de de los documentos aportados por los licitadores que afecten al contrato o a sus secretos industriales o comerciales.

\section{Confidentiality in resolution of the special appeal for contracts in the sector of Defense and Public Security and the Administrative Central Court for Contractual Appeals}

\footnotetext{
Abstract

The objective of this paper is to analyse public procurement in the defence and public security sector from the point of view of the measures that should be adopted in the decisions of the Public Procurement Review Central Administrative Court and the specialised authorities of the autonomous regions to protect the security of the information contained in public procurement documents and the confidentiality of the documents supplied by the bidders which affect the contract or their industrial or trade secrets.
}

Key words

Public sector contracts, Defence, Public security, Security of information,- Security of supply, Confidentiality, Military secrets, Industrial and trade secrets, Contractors and subcontractors, Functions of the Public Procurement Review Central Administrative Court and the specialised authorities of the autonomous regions. 


\section{INTRODUCCIÓN}

\section{Hacia un Mercado europeo de la Defensa: la Directiva 2009/81CE de 13 de julio de 2009}

La creación de la Agencia-Europea de Defensa en 2004 con la finalidad, entre otras, de fomentar la armonización de las necesidades operativas y la adopción de métodos de adquisición eficaces y compatibles (art45 Tratado UE) propició la ejecución de las directrices del Libro Verde, los “Contratos públicos de defensa" presentado por la Comisión de Comunidades Europeas (23 septiembre 2004). En este documento se analizaban los factores determinantes para la creación de un mercado europeo de defensa competitivo a la vista de sus peculiaridades y con el expreso propósito de superar la fragmentación que presentaba hasta aquel momento dicho mercado (se estimaba que los contratos públicos de defensa representaban una gran parte de la contratación publica en la Unión europea; los presupuestos de defensa de los Estados miembros tomados en su conjunto ascendían a 170.000 millones de euros de los cuales mas de 80.000 millones corresponden a contratos públicos) Al ser los Estados los clientes exclusivos, determinan la demanda de productos en función de unas necesidades militares vinculadas a objetivos estratégicos y definen así el tamaño de los contratos, incidiendo de este modo en los conocimientos técnicos, tecnológicos y de competitividad. Al propio tiempo, los Estados en su papel de reguladores controlan el comercio de armamentos por medio de licencias de exportación necesarias para las industrias, incluso para suministrar equipos dentro de la Unión y concesión autorizaciones para concursar.

Por todo ello, frente a una interpretación restrictiva del art. 296 del Tratado CE - (las disposiciones del presente Tratado no obstaran a las normas a que ningún Estado esta obligado a facilitar información cuya divulgación considere contraria a los intereses esenciales de su seguridad y en lo que se refiera al comercio de armas, municiones y material de guerra, estas medidas no deberán alterar las condiciones de competencia en el mercado común respecto de los productos que no estén destinados a fines específicamente militares)- que pudieran permitir una excepción a la concurrencia, se apostaba a la vista de la Comunicación interpretativa de la Comisión de 7 de diciembre de 2006 por la apertura de los distintos mercados de contratos de defensa al amparo de una futura Directiva con reconocimiento, sin embargo de las peculiaridades que afectaban a dichos contratos. En particular, se advertía de la necesidad de preservar la confidencialidad por imperativos de seguridad de los aprovisionamientos y de las fuentes suministros que debían garantizarse durante toda la vida de los programas de armamento desde la concepción hasta la retirada del servicio del equipamiento, tanto en tiempo de paz como en tiempos de guerra,.proveyendo a tal efecto: exigir garantías de suministro a los particulares; disponer equipos garanticen la superioridad tecnológica de las fuerzas militares; confidencialidad en programas y prescripciones técnicas; la obligación de proteger la información confidencial; exigiría a las industrias disponer previamente de autorizaciones especificas nacionales; establecer dispensas de publicidad etc. 
Como fruto de esta situación se dictaría la Directiva 2009/81/ CE de 13 de julio de 2009 "sobre coordinación de los procedimientos de adjudicación de determinados contratos de obras, de suministro y de servicios por las entidades o poderes adjudicadores en los ámbitos de la defensa y la seguridad y por la que se modifican las Directivas 2004/17/CE y 2004/18/CE". Se afirma en su Preámbulo que los equipos de defensa y seguridad son vitales tanto desde la óptica de la seguridad y de la soberanía de los Estados miembros, como de cara a la autonomía de la Unión y por ello tienen el carácter de "sensible" por lo que surgen exigencias en materia de seguridad del abastecimiento y de seguridad en la información. Estas exigencias se refieren sobre todo a las compras de armas, municiones y material de guerra (así como a los servicios y obras directamente vinculados), destinados a las fuerzas armadas, pero también a ciertas adquisiciones, particularmente sensibles en el ámbito de la seguridad no militar". La ausencia de un régimen a escala de la Unión en materia de seguridad en la información dificulta la apertura de los mercados de defensa y seguridad entre los Estados miembros, postulando en materia de información el reconocimiento mutuo de las habilitaciones nacionales de seguridad y permitir el intercambio de información clasificada entre entidades y poderes adjudicadores y las empresas europeas. Al mismo tiempo, los Estados miembros deben adoptar medidas concretas para mejorar la seguridad del suministro entre si con miras a la creación progresiva del sistema de garantías adecuadas (apartados 9 y 10). En función de estas características, el texto de la Directiva pasa revista a los distintos contratos de obras, suministros y servicios típicos del sector; justifica el ámbito de los contratos que quedan excluidos (en especial en materia de espionaje y contrainteligencia, o los encuadrables en el art. 296 del Tratado), sin perjuicio de proclamar la aplicación de los principios de trasparencia, objetividad igualdad de trato y no discriminación, en condiciones de competencia.

En cumplimiento de obligaciones en materia de transparencia y competencia, debe garantizarse un sistema eficiente de revisión de conformidad con la normativa comunitaria común que permita la posibilidad de impugnación del procedimiento de adjudicación antes de la firma del contrato, así como de garantías necesarias para que dicha revisión sea eficaz; "también debe existir la posibilidad de impugnar las adjudicaciones directas ilegales o los contratos celebrados en violación de la presente Directiva". Como modulaciones de este régimen general se significa con carácter general que "los procedimientos de recursos deben tener en cuenta la protección de los intereses de defensa y seguridad en relación con los procedimientos de los órganos de recurso, la elección de las medidas cautelares o las sanciones impuestas para castigar infracciones de las obligaciones en materia de transparencia y competencia”. Estos principios determinan la regulación de un Título IV sobre materias relacionadas con el Recurso (art. 55-60): efectos suspensivos: plazos; Organismos responsables de los procedimiento de recurso que cuando no tengan carácter judicial sus decisiones deberán ser motivadas; y cualificación profesional de sus miembros. En particular el art. 56.10 prescribe que los Estados miembros “velaran por que los Órganos responsables de los procedimientos de recurso garanticen un nivel adecuado de confidencialidad de la información clasificada o de otra información contenida en la documentación transmitida por las partes y actúe de conformidad con los intereses de la seguridad o defensa en todas las 
fases del procedimiento". A estos efectos, los Estados podrán disponer que únicamente los miembros de las instancias estén autorizados para manejar la información clasificada o imponer medidas de seguridad especificas relativas al registro de recursos,la recepción de documentos y almacenamiento de la documentación. También se impone a los Estados el deber de "conciliar la confidencialidad de la información clasificada con el respeto a los derechos de defensa" y en el caso que el recurso fuera examinado por un órgano judicial "lo hará de forma tal que el procedimiento respete en su conjunto el derecho a un juicio justo”.

\section{Irrupción de la Legislación sobre contratos en el sector de la defensa y seguridad en el proceso de reforma de la legislación de los contratos del sector público}

La irrupción de la Directiva 2009/81/CE anteriormente examinada en pleno proceso de reforma de la legislación de contratos del Sector público ha tenido consecuencias en el plano normativo y de técnica jurídica que es necesario exponer para el adecuado manejo interpretativo de los textos legales.

El nuevo régimen general de contratación publica adaptado a las Directivas comunitarias tuvo su expresión en la densa (309 artículos) y renovadora Ley 30/2007 de 30 d e octubre de Contratos del Sector Publico (en adelante LCSP 2007). Con independencia de otras reformas puntuales de dicha Ley, la mas profunda e importante tuvo lugar con ocasión de la Ley 34/2010 de 5 de agosto, motivada especialmente por la necesidad de adaptarse a la Directiva 2007/66/CE de 11 de noviembre que modificaría sustancialmente el régimen de los Recursos en materia de contratación. A raíz de aquella reforma, se incorporan materias como los supuestos especiales de nulidad y sustancialmente un nuevo Libro VI (art. 310 a 320) sobre el Recurso especial en materia de contratación y se opta precisamente en el ámbito de la Administración del Estado por al creación del Tribunal Administrativo Central de Recursos Contractuales (art. 311 y su puesta inmediata en funcionamiento (Disposiciones adicionales primera y segunda), ajustando además las repercusiones que la creación del nuevo órgano comportaban en el marco de la Ley de la Jurisdicción Contencioso-administrativa.

En pleno proceso de acoplamiento de esta nueva legislación se produce la publicación de la referida Directiva 2009/81 CE de 13 de julio de 2009 para el ámbito de la Defensa y la Seguridad. La incorporación de esta Directiva tendría lugar por la Ley 24/2011 de 1 de agosto de Contratos del Sector Publico en los ámbitos de la Defensa y la Seguridad (en adelante Ley CSPDYS). Dicha Ley consta de 68 artículos y nueve Disposiciones Adicionales, pero como resulta últimamente habitual en plena crisis de la técnica legislativa, a pesar de la rubrica de la Ley también se incorpora en forma de Apéndice (Disposición final Primera) una reforma de varios artículos puntuales de la LCSP 2007) y, en especial por lo que aquí importa,la modificación de su Disposición Adicional 24 ("Contratos incluidos en el ámbito del art. 296 del Tratado Constitutivo de la Comunidad Europea") que ahora se transforma con la siguiente redacción "la preparación, selección 102 y adjudicación de los contratos comprendidos en el ámbito de aplicación de la Ley 
24/2011 de 1 de agosto de 2011 de contratos del sector público en los ámbitos de la defensa y de la seguridad, así como las normas reguladoras del régimen de Subcontratación se regirán, en primer lugar por aquella y supletoriamente por la presente ley". Esta nueva redacción era en gran medida innecesaria puesto que, si exceptuamos la materia de la subcontratación, la referencia a la preparación, selección y adjudicación no es otra cosa que una simple reiteración del art. 4.1 de la propia Ley CSPDYS. A raíz de autorización contenida en Ley 2 /2011 de 4 de marzo de Economía Sostenible finalmente se ha promulgado por Real Decreto Legislativo 3/2001 de 14 de noviembre un texto refundido de la LCSP (en adelante TRLCSP 2011) de 334 artículos y múltiples Disposiciones Adicionales, manteniéndose aquella con el mismo texto que acaba de transcribirse si bien ahora figura como Disposición Vigésimo primera bajo la rubrica Contratos incluidos en los ámbitos de la Defensa y Seguridad del TR de LCSP de 2011).

El contenido de la referida Disposición Vigésimo primera del TRLCS 2011 puede a primera vista plantear algunos problemas sobre el ámbito de aplicación exacto. Efectivamente en la misma, se alude no a la Ley especial en bloque, sino en determinadas fases del procedimiento "preparación selección y adjudicación de los contratos comprendidos en el ámbito de aplicación de la Ley 24/2011 de 1 de agosto sobre defensa y seguridad" y en el de "las normas del régimen de subcontratación". Una interpretación literal de dicha Disposición al contrastarla con los distintas materias y títulos de la LCSPDYS podría concluirse que algunos títulos de esta ultima han quedado derogados al no corresponderse con aquella nomenclatura (como los relativos al Título Preliminar, Título I "elementos del contrato" o el mismo Título IV sobre Revisión de actos en los procedimientos de adjudicación). Sin embargo, esta no puede ser la conclusión procedente por los siguientes argumentos a) la LCSPDYS en bloque no ha sido derogada a la vista de la relación contenida en la Disposición Derogatoria Única del TRLCSP. A mayor abundamiento hay recordar que el Preámbulo de la Ley CSPDYS afirmaba que dicha ley "lejos de establecer un régimen de ruptura con la ley que rige con carácter general la contratación de los entes públicos, pretende enlazar directamente con ella y de esta forma extender la vigencia de los principios que la inspiran también al ámbito de la defensa y la seguridad"; b) si exceptuamos la referencia concreta a la Subcontratación la referida la supletoriedad prevista en Disposición Adicional Vigésimo primera del TRLCSP no tiene relevancia alguna para poder deducir que las materias no incluidas en aqueIla han quedado derogadas; c) muchos artículos de la LCSPDYS tras tipificar su especialidad se remiten expresamente de forma complementaria o parcial a concretos artículos con su numeración propia a la LCSP 2007, con lo cual se produce una aplicación directa y prioritaria de esta ultima. Precisamente, esta remisión textual a artículos o apartados de artículos de las LCSP 2007 plantea ahora el problema complementario al tener que identificar su artículo a la vista de la nueva enumeración derivada de TRLCSP de 2011. En aras a una técnica legislativa mas depurada hubiera sido mas congruente incluir la LCSDYS en la refundición del Texto Refundido de 2011 a fin de evitar conflictos interpretativos y favorecer una mayor comodidad en el manejo de los textos.

Con la promulgación de la LCSPDYS se completa para los contratistas y operadores el mercado interno de la contratación en el sector de Defensa y Seguridad que en 
el ámbito exterior e internacional había ya tenido una primera regulación con la Ley 53/2007 de 29 de diciembre sobre Control del Comercio exterior de Defensa y Doble Uso por el que se somete a autorización administrativa las exportaciones de dichos productos y material y se crea un Registro Especial de Operadores y una Junta Interministerial Reguladora del Comercio Exterior de material de Defensa y Doble Uso, adscrita al Ministerio e Industria. Recientemente, esta actividad contractual exterior ha tenido un desarrollo específico con ocasión del Real Decreto- Ley 19/2012 de 25 de mayo de medidas de liberalización del Comercio y otros servicios, en cuya virtud y al amparo del art 7. g) de la LCSPDYS, se instrumenta la realización de suministro de equipo militar sobre la base de un contrato previo entre el Gobierno español y un Gobierno extranjero para cuya ejecución el Ministerio de Defensa seleccionara, conforme a la normativa propia de la legislación contractual del sector a los contratistas, asumiendo aquel funciones de supervisión y vigilancia, sin perjuicio de que el contratista ostente la condición de exportador.

\section{II. ÁMBITO OBJETIVO Y SUBJETIVO DE APLICACIÓN DE LA LEY Y TIPOLOGÍA CONTRACTUAL EN EL SECTOR DE LA DEFENSA Y SEGURIDAD PÚBLICA}

Aunque nuestro propósito, en la presente ocasión, sea exclusivamente referirnos al ámbito de actuación del Tribunal Administrativo Central de Recursos Contractuales y,en su caso, de los organismos análogos de las Comunidades Autónomas resulta conveniente referirse sumariamente a algunos aspectos relevantes del contenido de la LCSPDYS.

\section{A) Ámbito de aplicación: objetivo y subjetivo}

El art. 1.1 de la Ley acota el ámbito contractual al que se aplica desde una doble dimensión a) regulación de la preparación y del procedimiento de adjudicación de los contratos de obras, suministro, servicios y colaboración entre el sector publico y sector privado que se celebren en al ámbito de la defensa y de la seguridad publica. Por lo tanto, la regulación sustantiva del contenido de estos contratos se regirá por normativa general prevista en el Texto Refundido LCSP 2011: y b) el régimen jurídico aplicable a "la subcontratación en dicho ámbito", ámbito que afecta a la posición del subcontratista en la fase de selección y adjudicación de dichos subcontratos y a la regulación parcial de su contenido sustantivo.

Por el contrario, se excluyen expresamente del ámbito de aplicación de la Ley: los contratos de Concesión de obras publicas: y el de gestión de servicios públicos, lo cual no implica que las Administraciones publicas competentes en defensa o seguridad publica no puedan utilizar para sus fines dichas figuras contractuales, si bien en este caso no les seria de aplicación la Ley Para los Contratos Administrativos especiales el art. 4 contempla una regla especifica en orden a que cuando los contratos contemplados en la Ley tengan alguna prestación de alguna otra figura contractual con-

104 templada o no en el Texto Refundido de la LCSP 2011 o en la Ley 31/2007 de 30 octubre 
de Sectores especiales solo será de aplicación LCSPDYS “cuando razones objetivas justifiquen la adjudicación de un solo contrato”. El mismo art. 4 exhorta a los Órganos de contracción "evitarán que la decisión de adjudicar un solo contrato se tome con el fin de eludir la aplicación de la presente Ley”.

El ámbito objetivo o marco de los contratos incluidos en al Ley viene constituido por dos bloques materiales a) la Defensa, configurada "como el conjunto de actividades reguladas en la Ley Orgánica 5/2005 de 17 de noviembre de la Defensa Nacional”. Dichas actividades comprenden las del Ministerio de Defensa, las Fuerzas Armadas (Ejercito de Tierra, la Armada y Ejercito del Aire, Estado Mayor de la Defensa y las misiones de carácter militar de la Guardia Civil (art. 23 y 24); Centro Nacional de Inteligencia (art. 25) y Cuerpo Nacional de Policía (según el art. 279 en tiempo de conflicto bélico y durante la vigencia el estado de sitio; y b) El ámbito de la Seguridad Publica, según el art. 1.2. lo constituye el conjunto de actividades no militares de las Fuerzas y Cuerpos de Seguridad publica dirigidas a la protección de las personas y de los bienes y a la preservación y mantenimiento del orden ciudadano dentro del territorio nacional y el conjunto de actividades desarrolladas por las autoridades aduaneras encaminadas a garantizar la seguridad y protección del territorio aduanero de la Unión europea, así como cualesquiera otras que se definen como tales en las leyes. Análogamente deberá tenerse en cuenta el Código Aduanero (Reglamento 450/2008 de 23 de abril de 2008; Servicio de Vigilancia Aduanero adscrito a la Agencia estatal de Administración Tributaria (OM Pre /3581/2007 de 10 diciembre).

Por ultimo, el ámbito subjetivo de aplicación se delimita remitiendo en concreto a los Poderes adjudicadores como Administraciones Publicas que se contempla en I TRLCASP 2011 y, en concreto a los efectos de esta Ley, a la Administración general del Estado a la Administración de las Comunidades Autónomas competentes en materia de seguridad publica y a los demás entes, organismos o entidades con personalidad publica o privada vinculadas a dichas Administraciones que ejerzan competencias en materia de defensa o de seguridad publica que no tengan carácter industrial o mercantil.

\section{B) Tipologías contractuales}

Dentro de la tipología de los Contratos regulados por la Ley y sometidos a Regulación armonizada a los efectos de determinar la competencia del Tribunal Administrativo Central de Recursos Contractuales en relación a la Defensa y Seguridad se comprenden:

Suministro y de Servicios cuyo valor sea igual o superior a $387.0000 €$; los contratos de Obras cuyo valor estimado sea igual o superior a 4.845.000 €.; $Y$ en todo caso los Contratos de Colaboración entre el Sector publico y el Sector privado.

Respecto a la especificidad de los contratos sometido al ámbito de la Ley se formulan las siguientes concreciones: 
- Suministro: art 2.1.a) deberá entenderse comprendidos los suministros de Equipos militares, incluidas las piezas, componentes y subunidades definidos conforme al punto 5 de la Disposición Adicional Primera como "el equipo específicamente diseñado o adaptado para fines militares destinado a ser utilizado como armas, municiones o material de guerra"; Suministro de armas y municiones destinadas al uso de las Fuerzas, Cuerpos y Autoridades con competencias en seguridad (deberá interpretar que se refiere a seguridad publica); y Suministros de Equipos Sensibles, debiéndose entender como tales, según la especificación n 6 de la Disposición Adicional Primera como "equipo con fines de seguridad pública que exija un nivel elevado de confidencialidad en razón de las circunstancias concurrentes debidamente justificadas o implicar, requerir o contener información clasificada" (incluidos piezas, componentes y unidades de los mismos).

- Por lo que afecta al Contrato de Servicios su caracterización se estructura a base de dos Anexos; en el primero de ellos se enumeran 20 modalidades (distintos tipos de transporte; telecomunicaciones, arquitectura, empieza; contabilidad, auditoría y teneduría de libros e informática) mientras que en el anexo II se comprenden seis modalidades (hostelera; transporte complementario y auxiliares; servicios jurídicos; colocación y suministro de personal; servicios sociales y de salud): esta distinción tiene su repercusión principal en los distintos procedimientos para su adjudicación.

- No se define o caracteriza propiamente el contrato de obras, si bien en el art. 2 se relacionan dos tipos de obras (relacionadas con los suministros o servicios) en relación a los equipos, armas y municiones y, en general con fines específicamente militares o bien obras sensibles (aquellas obras con fines de seguridad pública que exigen un nivel elevado de confidencialidad en razón de las circunstancias concurrentes debidamente justificadas o por implicar, requerir o contener información clasificada) y servicios sensibles (aquellos servicios con fines de seguridad pública que exigen un nivel elevado de confidencialidad en razón de circunstancias concurrentes debidamente justificadas o por implicar, requerir o contener información clasificada). Análogamente, se consideran como Servicios la investigación y el desarrollo.

- Finalmente, en todo caso se consideran comprendidos los contratos de colaboración entre el sector público y el sector privado que se regirá por las normas generales del Título I de la Ley y las especiales que le sean de aplicación, de acuerdo con el Texto Refundido de la LCSP 2011.

\section{C) Contratos excluidos}

En el marco de esta especialidad contractual, el art. 7 contiene una lista de contratos o negocios excluidos de la Ley. Respecto a estos contratos excluidos, se regirán por sus propias normas, todo ello sin perjuicio que la LCSPDYS se aplique para 
“resolver dudas y lagunas". En todo caso se advierte que los Órganos de contracción velarán para que "ninguna de las exclusiones previstas en este artículo sea utilizada con carácter abusivo para aludir la aplicación de la presente Ley”.

Una cierta colisión interpretativa puede producirse entre el art. 13. 2 c) y d) del TR LCSP 2011 y el art. 7 b) y c) de la LCSPDYS. Efectivamente en los preceptos citados de la primera de las Leyes, se excluyen de su consideración como contratos sujetos a regulación armonizada cualquiera que sea su cuantía los definidos en el art. 346 del Tratado Unión Europea que se concluyan en el sector de la Defensa (exclusión innecesaria, por otra parte, por estar comprendidos en el artículo 4.e del mismo texto) y "los declarados secretos o reservados, o aquellos cuya ejecución deba ir acompañada de medidas de seguridad especiales conforme a la legislación vigente o en la que se exija la protección de intereses esenciales para la seguridad del Estado". Para tal exclusión se requiriera a tal efecto una declaración que acredite de forma expresa esta circunstancia. Obviamente, esta exclusión procede de la redacción inicial de 2007 de la Ley de Contratos del Sector público que ha pasado íntegramente al Texto Refundido actual de la LCSP, con olvido que en el ínterin se había publicado la Ley LCSPDYS de 2011. En consecuencia de interpretarse estrictamente dicha exención del régimen de regulación armonizada en el ámbito de la Defensa y Seguridad prácticamente seria innecesaria la propia LSPDYS ya que todos los contratos armonizados contienen medidas de seguridad específicas o de protección de intereses esenciales. Por ello creemos que para salvaguardar la regulación armonizada de los contratos de Defensa y Seguridad no es necesario tener en cuenta esta exención, siendo suficiente la exclusión específica de su aplicación que se contiene en el art. 7.1 LCSPDYS en su apartado b (aquellos que de aplicarse la Ley resultaría necesario revelar información contraria a los intereses esenciales de la Seguridad o bien conforme al art. 346 Tratado Unión Europea pudieran resultar perjudicados los intereses esenciales de la Defensa o Seguridad Nacional) y b) los destinados a inteligencia, incluidas las actividades de contrainteligencia (letra d del art. 7).

\section{LA SEGURIDAD DE LA INFORMACIÓN Y LA GARANTÍA DE LA CONTINUIDAD DEL SUMINISTRO COMO ELEMENTOS TÍPICOS DE LA ESPECIALIDAD DE LA CONTRATACIÓN EN MATERIA DE DEFENSA Y SEGURIDAD PÚBLICA: SU EXTENSIÓN A LA SUBCONTRATACIÓN}

\section{Régimen aplicable a los contratistas}

El Preámbulo de la Ley CSPDYS, siguiendo los principios de la Directiva 2009/81 CE, especifica claramente que "dos son las ideas que sirven de guía a la Directiva citada. De una parte, el reconocimiento de que en los contratos relativos a la defensa y seguridad cobra especial relevancia, de una parte, la seguridad en la información que se transmite a los licitadores y la garantía en la continuidad del suministro; y de otra la necesidad de establecer ciertas normas que faciliten la flexibilidad en los procedimientos de contratación". 
A) En materia de Seguridad de la Información el art. 21.1 impone como principio general que el Órgano de Contratación especificara de forma resumidas en el Anuncio y de forma detallada en la Documentación del Contrato: "las medidas y exigencias necesarias para garantizar la Seguridad de la información al nivel requerido". Ahora bien, conforme a los arts. 26 (publicidad de las licitaciones) y art. 35.3 (publicidad de las Adjudicaciones), el Órgano de Contratación podrá "no publicar determinada información siempre que su divulgación pueda constituir un obstáculo para aplicar la legislación, sea contraria, al interés publico, en particular a los intereses de la defensa o la seguridad interior o perjudique a los intereses comerciales, legítimos, de candidatos y licitadores públicos o privados o pueda perjudicar la competencia leal entre ellos".

El Órgano de contratación deberá especificar de forma resumida en el anuncio y detalladamente en la documentación del contrato las medias y exigencias necesarias para garantizar la seguridad de la información a nivel requerido; al tiempo, que exigir que los Candidatos o licitadores estén en posesión de las correspondientes Habilitaciones en materia de Seguridad de Empresa y "en su caso de establecimiento, de conformidad en todo caso con el grado de clasificación de la información” (art. 21.2). Análogamente, para aquellos contratos que requieran "el uso de información clasificada o requieran el acceso a la misma”, el Órgano de Contratación deberá exigir a la empresa estar en posesión de las habilitaciones correspondientes en materia de seguridad de empresa, de establecimiento o equivalentes en materia de seguridad de la información (art 15.5). La protección a la información clasificada se extiende no solo a la que figure en la documentación contractual, sino la que se suministre al contratista a lo largo del procedimiento de licitación y adjudicación (art. 23.3). La presunción de falta de fiabilidad del contratista para cumplir estos requisitos puede incluso comportar el rigor de la declaración de la Prohibición de contratar al "haberse averiguado, sobre la base de cualquier medio de prueba, incluidas las fuentes de datos protegidas" que el empresario no "posee la fiabilidad necesaria para excluir los riesgos para la seguridad del Estado o para la defensa” (art. 12,1 b) de la Ley).

Esta exigencia también será aplicable a los Subcontratistas. A tal efecto los Órganos de Contratación podrán exigir que las proposiciones de los licitadores y subcontratistas asuman el compromiso de confidencialidad de toda la información clasificada que posean o que llegue a su conocimiento a lo largo de la duración del contrato y después de su terminación "de conformidad con las disposiciones legislativas, reglamentarias y administrativas pertinente”. El licitador deberá comprometerse además a exigir a los subcontratistas identificados y nuevos subcontratistas dicha confidencialidad a lo largo de la ejecución del contrato y suministra la información suficiente para determinar si cada uno de los subcontratistas poseen la capacidad para la salvaguardia de la confidencialidad de la información clasificada a la que tengan acceso o que vaya a generarse. En correspondencia a estas exigencias, el art. 23.2 proclama que el Órgano de contratación no divulgara la información facilitada por los candidatos o licitadores que estos "hayan designado como confidencial y, en particular, la información referente a secretos técnicos o comerciales y los aspectos confidencia108 les de las ofertas". 
Cabe advertir que la Ley utiliza las expresiones confidencialidad, seguridad de la información, grado de clasificación de la información clasificada o reservada, intereses de defensa o seguridad interior etc. a lo largo del articulado, pero sin definir su contenido sustantivo ni remitir a una legislación o normativa concreta existente sobre el particular. Únicamente, la Disposición Adicional Primera sobre “Definición de los términos a los efectos de la presente Ley" en su apartado 10 precisa que por Información Clasificada deberá entenderse "cualquier información o materia, independientemente de su forma, naturaleza o modo de transmisión, al que se haya atribuido un nivel de clasificación de seguridad o un nivel protección que en interés de la seguridad nacional y de conformidad con las disposiciones legales, reglamentarias o administrativas vigentes en el Estado, requiera protección contra toda apropiación indebida, destrucción, eliminación, divulgación, perdida o acceso por cualquier persona no autorizada o cuando cualquier otro riesgo". Esta definición es traslación de la propia Directiva -en la medida que pueda considerarse una norma jurídica en sentido estricto- no implica otra cosa que la remisión a la normativa vigente en nuestro Ordenamiento jurídico anterior a la Ley sobre esta materia. Todo ello sin perjuicio de tener en cuenta lo previsto en la Disposición Adicional Novena que anuncia que "el Gobierno en el plazo de tres meses desde la publicación de esta Ley, determinará las capacidades industriales y áreas de conocimiento que afecten a los intereses esenciales de la defensa y la seguridad nacional"; lo cual parece anunciar una futura legislación o normativa innovadora al respecto que pueda aportar alguna clarificación al respecto

Paralelamente, la Disposición Adicional Quinta prevé que los contratos que supongan el uso de información clasificada o requieran el acceso a la misma deberá tenerse en cuenta "las disposiciones reglamentarias que dicte la Autoridad Nacional de Seguridad para la Seguridad de la Información clasificada originada por las partes del Tratado del Atlántico Norte, por la Unión Europea y la Unión Europea Occidental”. Y en este orden de consideraciones llama la atención la mera remisión al ámbito reglamentario de una materia tan relevante, y, en particular, a la Orden PRE 2130/2009 de 31 de julio por la que se designa la Autoridad Delegada para la Seguridad de la Información Clasificada originada por dichos Tratados e Instituciones "o norma que la sustituya". A dicha Autoridad se le encarga la acreditación del candidatos o licitador en orden a la disponibilidad de la habilitación correspondiente y verificación del grado de habilitación de seguridad del establecimiento de que disponga el candidato o licitador, acreditación que deberá realizarse con anterioridad al momento que sea necesario para tener acceso a la información clasificada antes de la adjudicación del contrato. Se especifica en la Disposición Adicional referida que Órgano de contratación deberá tener establecido un órgano de control responsable de la información clasificada y garantizar una adecuada protección de la información clasificada.

A raíz de estas remisiones, en ultima instancia, la legitimidad de los contenidos restrictivos de la información en la documentación contractual por razones de seguridad y defensa del Estado deberán referirse a lo dispuesto con carácter general en el art. 41.b) de la Carta de los Derechos Fundamentales de la Unión Europea: art. 105,b) de la CE y en art. 37, 5 b) y d) de la 30/1992 de 26 de Noviembre LRJPAC. 
La normativa aplicativa de cabecera se basa principalmente en la Ley 9/1968 de 5 de abril sobre Secretos Oficiales (modificadas por Ley 48/1978) y su Reglamento aprobado por Decreto 242/1969; normas todas ellas de inspiración netamente preconstitucional y que solo en los años noventa del siglo pasado (Vid Sainz Moreno op. cit. y Álvarez Conde, Op. cit. 1997 pág. 351 y ss.) se intentaría elaborar un Anteproyecto de Ley Orgánica de Secretos Oficiales que finalmente no prosperaría. La doctrina especializada (Vid especialmente, entre otros Sainz Moreno y las monografías, de Pomed y de Mestre Delgado) vienen destacando las quiebras y, disfunciones, así como la falta de actualización que presenta la normativa y regulación vigente anclada todavía en la superada técnica de las materias clasificadas. Hay que anotar que finalmente por Real Decreto 139/2000 de 4 de febrero se creó la Comisión Superior Calificadora de Documentos Administrativos y por el Real Decreto 1708/2011 de 18 de noviembre se ha aprobado el Reglamento del Sistema español de Archivos y Registros (en cuyo art. 27 se excluye del acceso, a las materias reservadas).

Todo ello explica que en ámbito de la Contracción por razones de Defensa y Seguridad hasta el momento tenga que acudirse a regulaciones de ínfimo rango administrativo como; la Orden Ministerial Comunicada del Ministerio de Defensa; 17/2001 de 29 de enero por el que se aprueba "el Manual de Protección de Materias Clasificadas del Ministerio de Defensa en poder de las Empresas"; Orden Ministerial Comunicada 81/ 2001 de 20 de abril por la que se aprobaría las normas de Protección en Contratos del Ministerio de Defensa (BOE del Ministerio de la Defensa $n^{\circ} 84$ de 30 de abril de 2001); Orden Ministerial 76/2006 de 19 de mayo (BOE por el que se aprueba la Política de Seguridad de la Información del Ministerio de Defensa en la que se definen los principios básicos de Seguridad de la Información, distinguiendo entre Materias clasificadas y reserva institucional. En base a esta normativa se viene exigiendo a todo contratista con el Ministerio de Defensa que suscriba un "Acuerdo de Seguridad" en virtud del cual se compromete el exacto cumplimiento de las disposiciones previstas en la normativa vigente con la finalidad de garantizar la documentación y el material tanto entregado por el Ministerio como el elaborado por la propia empresa. El Acuerdo asignará al contratista un grado de clasificación de seguridad en función de las características de las materias clasificadas que vaya a manejar o custodiar en relación al Ministerio o a terceros. Obviamente, los nuevos postulados de la Ley CSPDYS exigirán una actualización de estas regulaciones a través de un rango normativo suficiente y apropiado para reforzar la colaboración y la confianza legítima de los contratistas, máxime en aquellos contratos como el de Suministro o el de Servicios que tienen una continuidad en las prestaciones. En otros Ordenamiento jurídicos como el Francés, estas materias también se regulan en detalle por normas de ínfimo rango pero al menos en un texto único completo, sumamente sistematizado y preciso (Vid Arrte 23 de julio de 2010 por el que se aprueba la Instrucción General Interministerial sobre Protección de Secretos de la Defensa Nacional). Al propio tiempo, cabe registrar la existencia de la "Commision Consultive du Secret de la Defense national" creada por la Ley 98-567 de 8 110 de junio de 1998 y que en año 2009 elaboraría y publicaría un interesante "Rapport 
1998-2004" que contiene un balance de su actuación y un profundo análisis de la problemática de este sector.

B) Conforme a la Disposición Adicional $1^{\mathrm{a}}$ relativa a la definición de términos utilizados en la Ley, por Seguridad en el Suministro se entiende el conjunto de requerimientos específicos que impone el Órgano de Contracción con el fin de asegurar,durante el ciclo de vida (todas las posibles etapas sucesivas de los productos desde su definición hasta su eliminación) de los equipos militares (equipos detonados a fines militares como armas, municiones, o material de guerra) o de los equipos sensibles (con fines de seguridad pública que exigen un nivel elevado de confidencialidad en razón de circunstancias concurrentes debidamente justificadas o por implicar o requerir o contener información clasificada). Estos requisitos que deberán ser identificados y descritos en la Documentación del contrato ya sea mediante relación detallada o por referencia a al legislación nacional específica "de rango reglamentario o superior" deberán versar sobre la ejecución del contrato (requisitos técnicos, operativos y de calidad, cumplimiento de plazos y ritmo de entregas) y la disponibilidad del apoyo logístico para la operación de los equipos, o infraestructuras y servicios con referencia especial a la capacidad de mantenimiento y reparación). La traslación de esta previsión tiene lugar en el art. 22 de la Ley, en cuya virtud el Órgano de contracción deberá especificar las correspondientes exigencias en la Documentación del Contrato y exigir, en su caso, que la Proposición u Oferta las incluya.

\section{Aplicación especifica a la sucontratación}

La LCSPDYS dedica el Título V (arts. 61 a 66) a la Subcontratación en el Sector, regulando no solo aspectos del proceso selectivo, sino también al contenido material o de fondo de la subcontratación. El Preámbulo de la Ley enfatiza la procedencia de la nueva regulación advirtiendo que: "mención especial merece la subcontratación, tema controvertido en el ámbito de la contratación pública en general y de manera especial en el de la defensa y la seguridad". No podemos en el espacio de este trabajo profundizar sobre esta cuestión, debiendo limitarnos a subrayar los aspectos relacionados con la seguridad de la información en el ámbito de la subcontratación y selección de subcontratistas.

- Salvo que el contrato o los pliegos dispongan lo contrario o que de su naturaleza se deduzca que haya de ejecutarse el contrato por el adjudicatario, el contratista podrá concertar con terceros la realización parcial de la prestación. En los Pliegos, el Órgano de contratación podrá exigir que los licitadores especifiquen en su oferta el porcentaje y la parte o partes del contrato que tiene la intención de subcontratar y el objeto de la subcontración a celebrar con cada uno de ellos y los cambios que se produzcan durante la ejecución del contrato, sin perjuicio que los Pliegos de Cláusulas particulares puedan especificar obligatoriamente porcentajes de subrogación (art. 61.1). 
- Como principio general, el art. 21 de la LCSPDYS prevé que el Órgano de contratación podrá incluir en el Anuncio de licitación y detalladamente en la documentación de la Contracción, la exigencia que los subcontratistas estén en posesión de las correspondientes habilitaciones en materia de seguridad de empresa de conformidad con el grado de clasificación de la información. Esta exigencia afectara a cualquier nivel de la cadena de subcontratación y se requerirá "la aprobación expresa y por escrito del Órgano de Contratación, previa a la subcontratación”, pudiendo además solicitar del adjudicatario o en su caso del licitador o candidato "certificación de que el subcontratista con el que se pretende iniciar la negociación dispone de las habilitaciones necesarias para acceder, almacenar, o manejar la información clasificada relativa al subcontrato".

- En el Pliego de Cláusulas Administrativas particulares se podrá atribuir al órgano de contracción, la facultad de rechazar a los subcontratistas seleccionados por el licitador en la etapa del procedimiento de adjudicación del contrato principal o por el adjudicatario durante el ejercicio del contrato. El rechazo deberá ser motivado y basarse necesariamente en el incumplimiento por el subcontratista "de las condiciones de aptitud o de solvencia establecidas en la selección de los licitadores para el contrato principal" y notificado por escrito al licitador o adjudicatario con "una justificación indicativa de los motivos por los que se considera que el o los subcontratistas no cumplen los criterios de selección" (art 62.1 y 2). Obviamente, entre las condiciones de aptitud se comprenderán todas las que hagan referencia a la seguridad.

- La Ley (art. 63) impone al licitador antes de la adjudicación del contrato o al adjudicatario determinadas obligaciones en orden a la adjudicación de los subcontratos (publicidad; observar los principios de transparencia, no discriminación e igualdad de trato a todos los que aspiren a la adjudicación y la posibilidad de celebrar acuerdos-marco con una duración no superior a siete años), debiendo en los Anuncios de Subcontratación indicar los criterios “de selección establecidos por el Órgano de contracción para la selección de los licitadores del contrato principal” y además "cualquiera otros criterios que se proponga aplicar para la seleccionar los subcontratistas". En el caso que ninguno de los subcontratistas o sus ofertas no satisfacen los criterios indicados en el Anuncio de subcontratación, o que de admitirlas "el adjudicatario no pueda cumplir los requisitos establecidos en el contrato principal, este podrá declarar desierta la licitación, justificando adecuadamente tales circunstancias" (art. 64).

\section{Su reflejo en los procedimientos de adjudicación}

Especial relevancia merece la incidencia de las normas de seguridad de la informa-

112 ción anteriormente analizadas en los procedimientos de adjudicación de los Contratos, 
pues conforme con lo expuesto en el Preámbulo, después de señalar que estos procedimientos se acomodan básicamente a la legislación general de Contratos (actualmente TR LCSP 2011), se afirma "con la única modificación importante de que el procedimiento negociado con publicación de anuncio de licitación, pasa a convertirse en un procedimiento ordinario, es decir al que pueden recurrir los órganos de contratación sin necesidad de justificación previa". Efectivamente se admiten los procedimientos ordinarios de Abierto (pudiendo incluir, no obstante, condiciones de ejecución relativas a la seguridad de la información y a la seguridad del suministro); Restringido (art. 39 a 42) y el Procedimiento Negociado (arts. 43 a 47), Sin embargo, para el Procedimiento Negociado con Publicidad no será necesario la concurrencia de condiciones o causas específicas justificativas (los arts. 170 a 175 del TR LCSP 2011), sino que, como indica el preámbulo, podrá convertirse en el procedimiento ordinario, con la especificación que el numero de empresarios al que se invite a participar en la negociación no podrá ser inferior a tres (siempre que las condiciones de mercado así lo permitan y con posibilidad de señalar el número máximo de participantes que en todo caso deberá ser suficiente para garantizar una competencia efectiva). No obstante, el art. 44 enumera los casos en que los Órganos de contratación podrán adjudicar contratos por procedimiento negociado sin publicidad previa de la Convocatoria de la Licitación para todos los contratos previstos en la Ley. Estos supuestos que son más amplios y flexibles que los previstos en el sistema general del Texto Refundido de CSP de 2011, y requieren su justificación en los “Pliegos y en los anuncios de adjudicación”. Paralelamente se admiten modulaciones por las razones de seguridad en la información, en el Diálogo Competitivo (procedimiento obligatorio en los contratos de colaboración publico-privado) y Acuerdos Marco (exención de la obligación de publicar el anuncio con los resultados de la adjudicación de cada uno de ellos).

Pese a que la Directiva europea prevé la posible adjudicación de algunos contratos a través de Juntas o Comisiones Centrales de adquisiciones, la LCSPDYS no contempla específicamente la Centralización de compras, a pesar que el BOE del día 13 de febrero de 2012 aprobaba el Plan Anual de Contratación centralizada del Ministerio de la Defensa para 2012, lo cual habrá que interpretar que esta modalidad de adjudicación se regulará por las normas comunes del TR LCSP 2011.

\section{LAS COMPETENCIAS DEL TRIBUNAL ADMINISTRATIVO CENTRAL DE RECURSOS CONTRACTUALES EN MATERIA DE RECURSOS SOBRE CONTRATOS DE DEFENSA Y SEGURIDAD PÚBLICA: LA COMPETENCIA DE LOS ÓRGANOS AUTONÓMICOS ESPECIALIZADOS EN MATERIA DE RECURSOS SOBRE CONTRACTOS DE SEGURIDAD PÚBLICA}

\section{1. Ámbito Competencial del Tribunal Administrativo Central}

El art. 59 de la Ley CSPDYS en materia del Recurso Especial en materia de Contratación se remite íntegramente para los contratos sometidos a Regulación Armonizada a lo dispuesto en legislación de contratos del Sector público (en la actualidad arts. 40 a 49 del 
TR LCSP de 2011 que sustituyen a los art. 310 a 319 de la LCSP de 2007), sin mas modificaciones que las relativas al ámbito competencial subjetivo y objetivo y a las reglas especificas de la confidencialidad que se examinaran con mas detalle en el apartado siguiente.

Desde el punto de vista de la cuestión competencial, se atribuye al Tribunal Administrativo Central de Recursos Contractuales la competencia para conocer y resolver el recurso especial en materia de Contracción relativos a los Contratos celebrados por los Órganos y entidades a que se refiere el art. 3 de la Ley, "integradas o dependientes de la Administración general del Estado”. Conforme a dicho art. 3.2 tienen la condición de Poderes Adjudicadores; la Administración General del Estado, que en materia de defensa corresponderá al Ministerio de Defensa, cuya Estructura orgánica ha sido recientemente reformada por Real Decreto 454/2012 de 5 de marzo y que en materia contractual las atribuciones de sus distintos órganos y dependencias en régimen de desconcentración está regulada por el Real Decreto 1053/2010 de 5 de agosto (BOE 11 de septiembre, modificado por el Real Decreto 1675/2011 de 18 de noviembre para adaptarlo precisamente a la LCSPDYS). Además en materia de Seguridad publica, con independencia de lo que más adelante se significará sobre las competencias de las CCAA en materia de seguridad pública, deberá atenderse a las competencias del Ministerio del Interior en la materia y a sus órganos periféricos (Delegaciones y Subdelegaciones del Gobierno en las Comunidades Autónomas.

Para el conocimiento de estos Recursos, a pesar que la Directiva 2009/81 CE permitía introducir modulaciones, la remisión de la Ley (art. 59.2) al régimen general del TRLCSP 2011 es completa (arts. 40 a 49) en cuanto al régimen de los actos recurribles; composición de los órganos, legitimación, solicitud de medidas provisionales (art. 43), procedimiento, tramitación y resolución y efectos de su resolución. Al mismo tiempo, el Tribunal Central también será competente para conocer de la llamada Cuestión por "Supuestos Especiales de Nulidad contractual" prevista en los arts. 56 a 58 de la Ley CSPDYS a la vista de la remisión específica al art. 311 LCSP (actual art. 41 del Texto Refundido de 2011). En esta materia, la remisión a los art. 37 a 39 del TR LCSP 2011 es también completa sobre supuestos y procedimiento de tramitación de la Cuestión. Las únicas excepciones, reconocidas en el art. 57 de la LCSPDYS, son las relacionadas con las consecuencias jurídicas de la Declaración de Nulidad en orden al mantenimiento de los efectos del contrato a) "cuando se acrediten razones imperiosas de interés general que afecten de modo esencial a intereses de la defensa o de la seguridad"; y b) "cuando las consecuencias de la ineficacia del contrato pusieran seriamente en peligro la existencia misma de un programa de defensa o de seguridad mas amplio que sea esencial para los intereses de la seguridad del Estado".

\section{Competencias de las Comunidades Autónomas en materia de Seguridad Pública: Órganos o Tribunales Autonómicos de Recursos Contractuales}

Conforme al art. 1.3 de la LCAPDYS se determina que a efectos de los contratos

114 regulados en la misma se entenderá por Seguridad pública "el conjunto de activida- 
des no militares de las Fuerzas y Cuerpos de Seguridad pública dirigidas a la protección de las personas y de los bienes y a la preservación y mantenimiento del orden ciudadano dentro del territorio nacional; el conjunto de actividades desarrolladas por las Autoridades Aduaneras encaminadas a garantizar la seguridad y protección del territorio aduanero de la Unión Europea, así como cualesquiera otros que se definan como tales en las leyes. El articulado de la Ley no siempre respeta una terminología uniforme en orden al alcance del concepto de Seguridad publica, pues en algunos preceptos se emplean expresiones que pueden inducir a cierta confusión como simplemente a Seguridad (art. 2.1.b; 57.2). Seguridad del Estado (art. 57.2, in fine) o Seguridad Nacional (Disposición Adicional Novena); seguridad interior (art. 35.3), seguridad no militar.

En términos de competencias constitucionales, el art. 149.1.29 CE atribuye al Estado en exclusiva la competencia sobre "Seguridad pública". Sin perjuicio de la posibilidad de creación de Policías especiales por las Comunidades Autónomas que se establezcan en los respectivos Estatutos en el marco de lo que disponga una ley orgánica. En base precisamente a estas competencias el art. 3 LCAPDYS al determinar el ámbito subjetivo de su aplicación considera como Poderes adjudicadores, además del Estado, a "las Comunidades Autónomas, de acuerdo con lo que se prevea en su respectivo Estatuto de Autonomía en el ámbito de la Seguridad publica”. Los Estatutos de Autonomía del País Vasco, Cataluña, Galicia, Navarra y Canarias reconocen competencias en la materia con la posibilidad de disponer de Policías propias autonómicas. El Estatuto de Cataluña (Ley Orgánica 6/2006 de 19 de julio) extiende la competencia sobre Seguridad pública a la Protección Civil (art. 132); Seguridad privada (art. 163: ejecución de la legislación estatal) y Video vigilancia y control de sonido y grabaciones en el ámbito público que se efectúen por la Policía o por empresas y establecimientos privados (art. 173). Respecto a esta última competencia la STC 31/2010 de 28 de junio (FJ 109) ha admitido su constitucionalidad en base al siguiente argumento jurídico: :las técnicas de video vigilancia y complementarias a que se refiere el art. 173 EAC constituyen una técnica instrumental necesaria para la actuación de la Policía autonómica que esta llamada, por sus cometidos, tanto a su empleo, como en su caso, al control de los sistemas de video vigilancias existentes. Podemos decir, por tanto, que al igual que la competencia estatal sobre el régimen de tenencia y uso de armas y explosivos (art. 149.1.26 CE) no impide el uso y tenencia por las Policías autonómicas, nada impide que ocurría, otro tanto respecto de la video vigilancia".

Precisamente en concordancia con esta especificidad competencial en el ámbito de la Seguridad Pública el art. 59.1 de la LCSDYS en su apartado 3 prescribe que en relación a los contratos sujetos a regulación armonizada que celebren las Comunidades Autónomas en el ámbito de la Seguridad Pública "será competente para conocer y resolver el recurso a que se refiere el aparato 1 (Recurso especial en materia de Contratación), el órgano que corresponda de acuerdo con lo dispuesto en el art. 311.2 de la Ley 30/2007 de 30 de octubre de 2007" (actual art. 41. 2,3 y 4 del Texto Refundido LCSP 2011). En base a este artículo se ofrecen tres posibilidades organizativas para las Comunidades Autónomas: a) crear un Órgano independiente (unipersonal o cole- 
gial, equivalente a un Tribunal Administrativo de Recursos Contractuales); b) atribuir la competencia para resolver los recursos al propio Tribunal central de Recursos Contractuales, previa suscripción de un convenio con la Administración del Estado y Asunción de gastos derivados de Asunción; c) establecer con carácter previo al Recurso especial, la opción por la necesidad de interponer un recurso administrativo. Las mismas opciones se ofrecen- en los supuestos que adjudicara contratos relativos a la seguridad pública en función de los umbrales a las Ciudades Autónomas de Ceuta y Melilla y en relación a las Corporaciones locales deberá estarse a lo que disponga la legislación autonómica y, en defecto de normativa específica al Órgano independiente creado para resolver los recursos relativos a estos recursos. Sobre los distintos modelos adoptados nos remitimos a los estudios contenidos en este número monográfico.

La única modulación a los órganos competentes en esta materia que impone el art. 60 1. de la Ley CSPDYS es la de que cuando se trate de procedimientos de adjudicación de contratos que afecten a la seguridad tramitados por las Comunidades Autónomas es la relativa a que "los órganos competentes en cada caso para conocer de los recursos deberán guardar el mismo nivel de confidencialidad indicado en el apartado anterior" (Tribunal Administrativo Central de Recursos Contractuales).

Por ultimo, debe apuntarse un posible conflicto interpretativo puntual. El art. 59.2 de la Ley CSPDYS otorga como hemos visto estrictamente competencias para resolver el Recurso especial en materias de Contratación a los órganos especializados de las Comunidades Autónomas que se constituyan; sin embargo, cabe preguntarse si análogamente esta competencia debe extenderse a la resolución de la Cuestión de nulidad (art. 58.1 de la misma Ley). Dada la remisión en bloque del art. 58.1 de la Ley CSPDYS al antiguo art. 311 de la Ley 30/2007 (actual 41 del Texto Refundido LCSP), habrá que entender implícitamente que los Órganos especializados de las Comunidades Autónomas también serán competentes para conocer de la cuestión de Nulidad en el ámbito estricto de las materias de seguridad pública.

\section{Sobre posibles competencias en materia de subcontratación}

A la vista de la nueva redacción derivada del art. 312 de LCSP (reforma de 2010) y actual art. 42 TR LCSP 2011 “podrán interponer el correspondiente Recurso especial en materia de contratación toda persona física o jurídica cuyos derechos intereses legítimos se hayan visto perjudicados o puedan resultar afectados por las decisiones objeto del recurso" cabe interrogarse sobre si el Subcontratista puede considerarse legitimado para la interposición del Recurso Especial ante el Tribunal Central de Recurso Contractuales en relación a los contratos de defensa y seguridad. Efectivamente, en la fase de ejecución del contrato es manifiesto que el subcontratista no puede considerarse ni parte ni tercero respecto al contrato ni ante la Administración publica; el art. 65 de la Ley CSPDYA lo descarta radicalmente, seña116 lando que los subcontratistas quedan obligados solo ante el contratista principal 
que asumirá la total responsabilidad de la ejecución del contrato frente a la Administración y esta responsabilidad no se verá alterada por "el conocimiento que tenga la Administración de los subcontratos celebrados por el adjudicatario o el ejercicio de las facultades a que se refieran los dos artículos anteriores" (normas sobre adjudicación y selección de subcontratistas). Ahora bien,lo cierto es que en la fase de preparación de la documentación contractual (Pliegos de Cláusulas y demás documentos contractuales) y exigencias de habilitaciones y condiciones de seguridad de la información y del suministro así como los contactos previos entre Órgano de contratación y subcontratistas -conforme hemos destacado en las referencias a la subcontratación- resultaría muy difícil no considerar al Subcontratista como titular de intereses legítimos a los efectos del art. 42 del TR Ley CSP 2011 y, por lo tanto, debería reconocérsele la condición de interesado ante el Órgano de resolución del Recurso especial en materia de contratación especialmente en aquellos aspectos estrictamente procedimentales que pudieran haberle ocasionado lesiones la actuación de los Órganos de contratación, estrictamente, en las fases preparatorias y selectivas del contrato principal.

\section{LA PROBLEMÁTICA DE LA CONFIDENCIALIDAD EN EL PROCEDIMIENTO DE ACTUACIÓN DEL TRIBUNAL ADMINISTRATIVO CENTRAL Y DE LOS ÓRGANOS ESPECIALIZADOS DE LAS COMUNIDADES AUTÓNOMAS}

\section{Actos recurribles: la documentación contractual y el expediente de recurso}

Como hemos afirmado anteriormente el art. 59.1 y 4 de la LCSPDYS se remite íntegramente en lo que afecta al Recurso Especial en materia de Contratación en orden a la impugnación de "actos y tramites" a los actuales art. 40 a 50 TR LCSP 2011. Dichos artículos se refieren tanto a los actos impugnables como a la iniciación, y tramitación del procedimiento de recurso, así como a la legitimación y efectos de la resolución que se adopte. En consecuencia en la legitimación, tramitación, resolución del procedimiento de recurso serán aplicables dichas normas generales con las específicas modulaciones o excepciones que imponga la LCSPDYS. A tal efecto, conviene tener en cuenta las siguientes referencias:

- En cuanto a los actos y trámites podrán ser impugnados con arreglo al art. 40.2 TR LCSP 2011: Documentación contractual (anuncios licitación, Pliegos y Documentos Contractuales); Actos de trámite en el procedimiento de adjudicación (decida tan directa o indirectamente sobre la adjudicación, determinen imposibilidad de continuar, o indefinición o perjuicio irreparable a derechos o intereses legítimos); Acuerdos de Adjudicación; los restantes defectos de tramitación podrán ser alegados al recurrir los actos de adjudicación. Conforme al art. 43 antes o después de la interposición del recurso, las personas legitimadas podrán solicitar adopción de Medidas provisionales (corregir infracciones de procedimiento o impedir que se causen perjuicios a intereses afectados e incluso las destinadas a suspender o hacer que se suspenda el 
procedimiento de adjudicación del contrato en cuestión o la ejecución de cualquier decisión adoptada por los Órganos de contratación.

- En la tramitación del procedimiento del recurso(arts. 46 y 47 LRJPAC) serán de aplicación las disposiciones de la Ley 30/1992 de 26 d e noviembre LRJPAC con las siguientes especialidades, además del escrito de interposición del recurso; figuraran en el procedimiento los siguientes tramites e intervenciones a) el Órgano de contratación deberá remitir al Tribunal el Expediente administrativo contractual acompañado de un informe.; b) traslado por el Tribunal del recurso a "los restantes interesados para formular alegaciones"; c) decidir sobre las medidas provisionales de suspensión; d) apertura de un periodo de pruebas “cuando los interesados lo soliciten o el órgano encargado de la resolución del recurso no tenga por cierto los hechos alegados por los interesados o la naturaleza del procedimiento lo exija podrá acordarse la apertura de un periodo de prueba por plazo de diez días aviles a fin de que puedan practicarse cuantas juzguen pertinentes"; podrán rechazarse las pruebas propuestas por los interesados cuando sean manifiestamente improcedentes o innecesarias, mediante resolución motivada; e) resolución motivada del recurso y congruente con las peticiones "se pronunciará sobre la anulación de las decisiones ilegales adoptadas durante el procedimiento de adjudicación, incluyendo la supresión de las características técnicas, económicas y financieras discriminatorias contenidas en anuncio de licitación, anuncio indicativo, pliego, condiciones reguladoras del contrato o cualquier otro documento relacionado con la licitación o adjudicación, así como, si procede sobre retroacción de actuaciones"; si como consecuencia del contenido de la resolución fuere preciso que el órgano de contratación acordase la adjudicación a otro licitador, se le concederá el plazo para presentación de documentación requerida por el art. 151 de la misma Ley. Análogas normas procedimentales serán de aplicación a la interposición de la Cuestión de Nulidad, salvo especialidades de plazos y no suspensión automática (art. 58.5 LCSPDYS).

- A la vista del anterior contenido deberá distinguirse entre a) la Documentación aportada por el Órgano de Contratación que constituye propiamente el Expediente de Contratación, integrado por toda la documentación generada por la licitación de los contratos mas, en su caso, el contenido de las distintos documentos técnicos y ofertas de todos los licitadores participantes y; b) la Documentación generada en el seno del procedimiento del recurso (escrito de interposición: alegaciones de las partes, pruebas y resolución del Recurso). Esta distinción es relevante a los efectos de la aplicación de los preceptos sobre audiencia de los interesados en las LRJPAC en la fase de instrucción (art. 84.1 que excluye informaciones y datos a que se refiere el art. 37.5 y entre los relativos a la Defensa nacional y seguridad del Estado) y en la vía de recurso (art. 112). Y ello resulta relevante dado a la legitimación para la interposición del recurso, el art. 42 del TR LCSP 2011 reconoce una amplísima legitimación para interponer los recursos a " toda persona física o jurídica cuyos 
derechos o intereses legítimos se hayan visto perjudicados o puedan resultar afectados por las decisiones objeto del recurso"; análoga legitimación se reconoce para solicitar la adopción de Medidas provisionales.

Sera precisamente en la fase de solicitud de medidas provisionales o de impugnación contractual cuando se desaten las tensiones competitivas entre adjudicatarios vencedores y licitadores excluidos o vencidos y en la que el acceso a la documentación contractual o la aportada por los partícipes en el contrato adquiera una relevancia especial en orden a su conocimiento e instrumentación de sus respectivos derechos a la defensa procedimental.

En este contexto, por lo tanto en los contratos de Defensa y Seguridad publica, deberá moderarse por el Tribunal, por una parte los intereses por la información reservada obrante por razones de defensa y seguridad y, por otra la legitima reserva por los secretos comerciales e industriales contenidos en las respectivas ofertas de los licitadores. Todo ello requiere de un equilibrio delicado que en alguno de sus aspectos ha sido abordado jurisprudencialmente, por lo que se considera conveniente antes de referirnos al derecho positivo aludir a dicha jurisprudencia.

\section{La confidencialidad en la información clasificada y la protección de los secretos industriales y comerciales en la normativa y jurisprudencia europea: la doctrina de la sentencia TJUE: 2008 "VARAC"}

El art. 56.10 de la Directiva 2009/81/ CE de 13 de julio de 2009 exige a los Estados miembros que los Órganos responsables de los Procedimientos de Recurso "garanticen un nivel adecuado de confidencialidad de la información clasificada o de otra información contenida en la documentación transmitida por las partes y actúen de conformidad con los intereses de seguridad o defensa en todas las fases del procedimiento". En el plano operativo la Directiva formula las siguientes medidas y recomendaciones; a los Estados miembros: a) posibilidad de decidir que un "organismo determinado es el único facultado para revisar contratos en los ámbitos de la seguridad y defensa"; b) disponer que únicamente los miembros de las instancias de recurso debidamente autorizados para manejar información clasificada puedan examinar los recursos que supongan el uso de dicha información; c) imponer "medidas de seguridad específicas relacionadas con el régimen de recursos, la recepción de documentos y el almacenamiento de documentación". Todas estas medidas deben ser lógicamente compatibles con los derechos de los recurrentes en el sentido de "conciliar la confidencialidad de la información clasificada con el respeto a los derechos de defensa" e incluso en el caso que el recurso sea examinado por una instancia judicial o un tribunal (en el sentido del art. 234 del Tratado) lo harán de forma tal que el procedimiento respete, en su conjunto, el derecho a un juicio justo. Además el art. 6 de la Directiva precisa con carácter general para entidades o poderes adjudicadores que, con independencia de las normas de publicidad y de información "no divulgara la información facilitada a los operadores económicos que estos hayan designado 
como confidenciales. Dicha información incluye en particular los secretos técnicos o comerciales y los aspectos confidenciales de las ofertas".

Por lo tanto, como puede observarse deben ser objeto de protección en orden a la confidencialidad tanto la información clasificada contenida en la Documentación Contractual como la información confidencial facilitada por los licitadores o adjudicatarios de los contratos de públicos en materia de defensa y seguridad. Las previsiones de la Directiva vienen a recoger en gran medida las conclusiones de la Jurisprudencia comunitaria en particular la Sentencia del Tribunal de Justicia (Sala Tercera) de la UE de 14 febrero de 2008, Asunto VARAC C-450/06. En el que se debatía precisamente un contrato publico en el ámbito de la Defensa y que resulta muy ilustrativo en relación al tema que nos ocupa.

El Litigio se originaría precisamente por la convocatoria de un contrato público para adjudicación de un suministro "de eslabones de orugas por carros de combate tipo “Leopardo”'. Presentaron ofertas dos empresas VAREC, SA y DIEHL, siendo adjudicado por el Ministerio de Defensa de Bélgica a esta última empresa por considerar que la de VAREC no reunía los requisitos de selección de carácter técnico y que su oferta era irregular. Impugnada por VAREC la adjudicación ante el Consejo de Estado, el Ministerio de Defensa no incluyo en el expediente la oferta de DIEHL. VAREC y el Auditor del Consejo de Estado solicitaron formalmente que se incluyera la referida oferta; el Departamento de Defensa arguyo que los planos y elementos constitutivos de los eslabones habían sido ya devueltos a DIEHL y si resultaba imprescindible que aquellos figuraran en el expediente del recurso debían solicitarse expresamente de esta última empresa dada el conflicto entre ambas empresas por la propiedad intelectual por los planos. DIEHL se negó expresamente a facilitar dichos planos por contener datos e informaciones confidenciales relacionadas con secretos comerciales. El Estado belga se opuso a la petición del Auditor de anulación del acto de adjudicación por falta de colaboración leal por parte de DIEHL para obtener una buena administración de justicia y ante esta disyuntiva el Consejo de Estado decidió suspender el procedimiento y plantear al Tribunal de Justicia la Cuestión Prejudicial, en relación al art. 1.1 de la Directiva 89/665/CEE y art. 15.2 de la Directiva 93/36: sobre si debe interpretarse que el Organismo responsable de los procedimientos de recurso debe garantizar la confidencialidad y el derecho a la protección de los secretos comerciales contenidos en los expedientes que le comuniquen las partes en la causa, incluida la entidad adjudicadora, sin perjuicio de que el propio organismo pueda conocer y tomar en consideración dicha información.

En la motivación de la Sentencia se invocaron principalmente los siguientes argumentos: si bien el objeto principal de las normas comunitarias sobre contratación era la apertura a la competencia no falseada en todos los Estados miembros, debe evitarse que las entidades adjudicadoras no divulguen información de los contratos cuyo contenido pueda ser utilizado para falsear la competencia, ya sea en el procedimiento de adjudicación o en ulteriores procedimientos, al tiempo que en virtud de principio de la confiaba legitima entre entidades adjudicadoras y operadores económicas, 120 sin miedo que se divulgue información a terceros que puedan perjudicar a los opera- 
dores. Si bien estos principios son directamente aplicables al procedimiento de adjudicación: "hay que reconocer que su eficacia se vería seriamente comprometida si, en un recurso interpuesto contra una decisión adoptada por una entidad adjudicadora relativa a un procedimiento de adjudicación de un contrato publico, toda la información sobre este procedimiento debería ponerse sin límite alguno a disposición del autor de dicho recurso o incluso de otras personas como las partes coadyuvantes". Ello además de poder falsear la competencia, podría incluso incitar a "interponer recursos con el único objetivo de acceder a los secretos comerciales de sus competidores". Por todo ello se estima que en un procedimiento de recurso en materia de adjudicación de contratos, el Organismo responsable de este procedimiento "debe poder decidir que no se transmita a las partes ni a sus abogados una información contenida en el expediente relativo a la adjudicación cuando sea necesario para garantizar la protección de la competencia leal o de los intereses legítimos de los operadores económicos que persigue el derecho comunitario".

Para sustentar esta "ratio decidendi", el Tribunal se planteó su compatibilidad con art. 6 del Convenio Europeo para la Protección de los Derechos Humanos y en particular el principio de contradicción entre las partes, a obtener pruebas y alegaciones y discutirlas ante el juez, así como respecto a la jurisprudencia dictada sobre esta materia. A tal efecto se considero que el principio de contradicción no es absoluto e ilimitado a toda información, debiendo ponderarse dicho principio con el derecho de otros operadores económicos "a la protección de su información confidencial y de sus secretos comerciales". Por ello los organismos deben "antes de comunicar dicha información a una de las partes litigantes, dar al operador económico de que se trate de la posibilidad de alegar el carácter confidencial o de secreto comercial de aquella".

La Sentencia del Tribunal de Justicia finalmente acordaría que debía interpretarse que "el Organismo responsable de los procedimientos de Recurso previstos en el art. 1.1 de la Directiva 89/665/CEE del Consejo de 21 de diciembre de 1989, debe garantizar la confidencialidad y el derecho a la protección de los secretos comerciales en relación con la información contenida en los expedientes que le comuniquen las partes en la causa, en particular a la entidad adjudicadora, sin perjuicio de que el propio organismo pueda conocer y tomar en consideración dicha información". Añadiendo que "corresponde a dicho organismo decidir como y en que medida es preciso garantizar la confidencialidad y el secreto de dicha información, habida cuenta de las exigencias de la protección efectiva y del respeto al derecho de defensa de las partes en el litigio y, en el supuesto de un recurso judicial o de un recurso ante un órgano jurisdiccional en el sentido del art. $234 \mathrm{CE}$ a fin de que el procedimiento respete en su conjunto, el derecho a un proceso justo".

\section{Alcance de las medidas de confidencialidad}

Tras estas directrices interpretativas, podemos pasar revista a su incidencia en el específico que nos ocupa: 
A) En el ámbito general de la Contratación, el actual art. 46.5 del TR LCSP 2011 al regular la tramitación del procedimiento del Recurso especial reconoce con carácter general que a) se garantizara "la confidencialidad y el derecho a la protección de los secretos comerciales en relación con la información contenida en el expediente de contracción, sin perjuicio que pueda conocer y tomar en consideración dicha información a la hora de resolver"; y b) que corresponde al Órgano competente que conoce del Recurso especial "resolver acerca de cómo garantizar la confidencialidad y el secreto de la información que obre en el expediente de contratación, sin que por ello, resulten perjudicados los derechos de los demás interesados a la protección jurídica efectiva y el derecho de defensa en el procedimientos".

B) Evidentemente en el ámbito especial de la contratación en materia de Defensa y Seguridad pública las anteriores previsiones son de aplicación directa, pero resultan insuficientes y ello explica que los arts. 59 y 60 de la LCSPDYS hayan adoptado las siguientes medidas que podemos estructurar conforme al siguiente esquema, aplicables tanto al Tribunal Administrativo Central de Recursos Contractuales como a los Órganos especiales de las Comunidades Autónomas competentes en materia de seguridad pública:

- Para la tramitación y resolución de los Recursos que hagan referencia a "información clasificada", los Departamentos ministeriales implicados "autorizaran a los miembros del Tribunal para manejar información clasificada al objeto de que puedan examinar los recursos que conlleven el uso de tal información" (art 59.2). El conocimiento de la información de materias clasificadas en las categorías de "secreto" o "reservado" para el contrato en concreto que se contengan en la documentación contractual requerirá la autorización del Ministerio de Defensa o del Ministerio del Interior (y eventualmente de las Consejerías de las Comunidades Autónomas en materia de seguridad pública) para conocer su contenido textualmente "manejar información clasificada al objeto de que puedan examinar los recursos" a los efectos de la resolución del recurso. La autorización parece que deberá solicitarse específicamente de dichas autoridades, previa su justificación, por parte del Presidente del Tribunal; aun cuando podría la iniciativa partir del propio Organismo de contratación que al remitir el expediente de contratación al Tribunal contuviera ya esta autorización. La información clasificada por la autorización no perderá su carácter por lo que en la motivación de la resolución del recurso no podrá desvelarse pero si aludir a su contenido y grado de influencia o vinculación que pueda tener en la resolución. Obviamente, esta información reservada no podrá ser conocida por los recurrentes a efectos de petición de Medidas provisionales, alegaciones y de prueba, lo cual puede incidir manifiestamente en el derecho a la defensa de los recurrentes.

- El Tribunal Administrativo Central de Recursos Contractuales (y el Órgano especializado de las Comunidades Autónomas en los contratos que afecten 
a la seguridad) "garantizarán un nivel adecuado de la confidencialidad de la información 'clasificada o no' contenida en la documentación transmitida por las partes" (art. 60.1). Esta previsión parece afectar exclusivamente a la documentación que los licitadores o adjudicatarios han aportado al expediente de contratación (toda la documentación generada por la misma clasificación, solvencia, certificaciones, garantías etc.) y en especial las Ofertas, tanto en sentido económico como en orden a las relativas a los secretos industriales y comerciales de los proyectos. Si bien los recurrentes podrá señalar los documentos que consideran confidenciales -además de las indicaciones que se contengan en el informe de remisión de la documentación a cargo del Organismo de contratación- corresponderá al propio Tribunal la decisión sobre el nivel adecuado de confidencialidad del expediente contractual y de recurso ponderando dichas exigencias con el derecho a la defensa (art. 60.2). A tal efecto, podrán arbitrarse distintas técnicas: como impedir sacar fotocopias de determinados documentos, consulta de documentos en presencia de un miembro del Tribunal; exigencia de un compromiso de confidencialidad al consultar los documentos declaración anticipada con la calificación de confidencialidad de la impertinencia de solicitar determinadas pruebas etc.

- Complementariamente, se prevé que por vía reglamentaria "se establecerán medidas de seguridad específicas relacionadas con el Registro de Recursos, la Recepción de documentos y el archivo y custodia de documentos" (art. 59.2). Esta faceta de la confidencialidad es específicamente instrumental y, por lo tanto, propia de un procedimiento garantista típico y de técnica documental. Conforme a la Disposición Final Tercera la potestad reglamentaria para el desarrollo de la LCSPDYS corresponde al Gobierno. Hasta el momento no conocemos que se haya dictado alguna norma reglamentaria sobre el particular.

- Se dispone concretamente que el Tribunal y, en su caso, el Organismo especializado de la Comunidad Autónoma, "actuara en todo caso de conformidad con los intereses de la seguridad o de la defensa en todas las fases del procedimiento" (art. 60.1). La referencia a las fases del procedimiento (interposición, medidas provisionales, instrucción y resolución) apunta que la salvaguarda de estos intereses lo será a los solos efectos procedimentales y no al contenido o fondo de las resoluciones que se adopten en cada una de estas fases, puesto que ello implicaría condicionar la autonomía u objetividad de las decisiones del Tribunal. Todo ello sin perjuicio de la garantía de "la confidencialidad y el secreto de la información que obre en el expediente de contratación, sin que por ello resulten perjudicados los derechos de los demás interesados a la protección jurídica efectiva y el derecho a la defensa en el procedimiento" (art. 60.2). A mayor abundamiento, como puntualiza la Directiva 2009/2011, esta protección a la defensa deberá también extenderse a la vía jurisdiccional que revise las resoluciones del Tribunal central y de los Organismos autonómicos. 
- No contiene, por el contrario, el art. 60 LCSPDYS una referencia específicas a la protección de los secretos industriales y comerciales en la fase de resolución de los recursos contractuales en relación con la información contenida en el expediente del recurso contractual, cuestión ésta de gran trascendencia cuando la experiencia pone de relieve que muchos licitadores pueden usar exclusivamente la vía del recurso para tener acceso a dichos datos o secretos de los otros licitadores. Ahora bien de diversos artículos de la misma Ley se deduce que esta precaución esta presente en misma. Así el art. 23 de las misma Ley impone a los Órganos de Contratación la no divulgación de la información facilitada por los candidatos o licitadores que estos hayan designado como confidencial y, en particular, la información referente a secretos técnicos y comerciales y los aspectos confidenciales de las ofertas; el art. 26.5 faculta para la no publicación por el Órgano de Contracción de información que "perjudique los intereses comerciales legítimos de candidatos o licitadores públicos o privados o pueda perjudicar la competencia lean entre ellos", y análogamente en relación a la adjudicación del contratos (art. 35.3).Esta laguna en la fase de resolución de los recursos deberá colmarse con la referencia genérica de protección dispensada con carácter general por el art. 46.5 del Texto Refundido de 2011, aplicable por vía de supletoriedad, aun cuando hubiese sido deseable una mayor atención a este problema dado las connotaciones y especializaciones tecnológicas cada día mas presentes en este sector de la contratación.

\section{COLABORACIÓN DEL TRIBUNAL CENTRAL DE RECURSOS Y LOS ÓRGANOS ESPECIALES DE LAS COMUNIDADES AUTÓNOMAS CON LA COMISIÓN NACIONAL DE LA COMPETENCIA PARA DENUNCIAR LAS PRÁCTICAS CONTRARIAS A LIBRE COMPETENCIA POR PARTE DE LOS LICITADORES Y CONTRATISTAS}

La salvaguardia de la libre competencia en el marco de la Contratación pública es un principio rector de normativa europea y de la nacional sobre la materia (art. 1 del TR LCSP de 2011). De ahí la necesidad de instrumentar mecanismos de colaboración entre los Órganos de contratación y la Comisión Nacional de la Competencia (Ley 15/2007 de 3 de julio). La redacción primitiva de la LCSP de 2007 incluiría una Disposición Adicional $27^{\mathrm{a}}$ bajo la rubrica de "Practicas contrarias a la libre competencia" en la que se configuraban como organismos legitimados para poner en conocimiento de la Comisión Nacional de la Competencias las infracciones de las que tuvieren noticia en el ejercicio de sus funciones. Inicialmente ostentaban legitimación únicamente los Órganos de Contratación y la Junta Consultiva de Contratación Administrativa. La Ley 34/2010 de 5 de Agosto de reforma parcial de la LCSP amplío esta legitimación a los Órganos encargados de Resolución de los Recursos especiales y al mismo tiempo se ha recogido también en la Disposición Adicional $23^{\text {a }}$ del Texto Refundido LCSP 2011.

Por su parte la Disposición Adicional $8^{\circ}$ de la LCSPDYS recoge análogamente esta

124 legitimación a favor del Tribunal Administrativo Central de Recursos Contractuales y 
de los Organismos especializados de las Comunidades Autónomas para; a) poner en conocimiento a la Comisión Nacional de la Competencia (Ley 15/2007 de julio y su Reglamento Real Decreto 261/2008 de 22 de febrero) “cualesquiera hechos de los que tenga conocimiento en el ejercicio de sus funciones que pueda constituir infracción de la legislación de defensa de la competencia", y b) en particular "comunicará cualquier indicio de acuerdo, decisión o recomendación colectiva, o practica concertada o conscientemente paralela entre los licitadores que tengan por objeto, produzcan o puedan producir el efecto de impedir, restringir o falsear la Competencia en el proceso de contratación". En especial deberán tenerse en cuenta la denuncia de las prácticas prohibidas por la Ley 3/1991 de enero -modificada por la Ley 29/2009 de 30 de diciembre- sobre Competencia Desleal. La LCSPDYS se limita a enunciar esta colaboración con la Comisión Nacional de Competencia que como Administración independiente será la competente para incoar los procedimientos e imponer las sanciones correspondientes, si bien deja imprejuzgados los efectos que sobre el contrato en concreto sometido al conocimiento del Tribunal Administrativo de Recursos Contractuales pueda tener la apreciación de oficio o a instancia de los recurrentes de la existencia de prácticas contrarias a la libre competencia. Uría Fernández (op. cit. 2010 pags. 93-107), después de denunciar tempranamente con carácter general la insuficiencia en la coordinación entre la legislación Contractual con la de la Competencia sugería que la solución mas apropiada era la de decretar por parte de la Comisión Nacional de la Competencia la suspensión del contrato, sin perjuicio de la correspondiente revisión jurisdiccional de la misma. Sin embargo, a raíz de las reformas posteriores de la LCSPDYS y TR LCSP 2011 (art. 43-48) cabría perfectamente entender que si el Tribunal Administrativo Central apreciara con ocasión del conocimiento de un Recurso infracciones a la legislación de defensa de la competencia o de la competencia desleal, bien derivadas de la impugnación de los Pliegos, Ofertas y de la documentación contractual, bien de hechos producidos durante el proceso de adjudicación del contrato, además de comunicar los hechos a la Comisión Nacional de la Competencia podrá acordar la suspensión del contrato como medida cautelar solicitada; e incluso, en su caso, pronunciarse directamente sobre la nulidad del contrato por la concurrencia de dichas infracciones por aplicación supletoria de los arts. 89.2 y 113 de la LRJPAC -previa audiencia de las partes- a la vista que el art. 47 TR LCSP 2011 ya que permite decretar la anulación de decisiones ilegales durante el procedimiento de adjudicación, tales como "supresión de las características técnicas, económicas o financieras discriminatorias".

Esta colaboración por unos Órganos cualificados como el Tribunal Administrativo Central o los Organismos autonómicos puede revestir importancia si se tiene en cuesta la estructura y el porvenir de la industria militar española que con la nueva normativa se verá afectada por la competencia extranjera y, en el orden interno, por el protagonismo que va a revestir la Subcontratación especialmente en ámbitos de marcado carácter tecnológico y de investigación. Se estima en torno a quinientas las empresas españolas dedicadas al sector de la industria de la defensa, agrupadas en una patronal TEDAE (Asociación española de Tecnologías de Defensa, Aeronáutica y Espacio; constituida en 2009 en sustitución de la anterior AFARMADE), pero en las 
que destacan por su posición las cuatro grandes procedentes de empresas públicas privatizadas: INDRA; EADS: Casa; (antigua Construcciones Aeronáuticas, S.A.) NAVANTIA (antigua empresa nacional Bazan) y GENERAL DYNAMICS, SANTA BÁRBARA, (antigua Santa Bárbara). En consecuencia, el observatorio que ofrece la resolución de los recursos contractuales y las cuestiones especiales de nulidad es muy relevante para detectar las posibles infracciones a la competencia y, en especial, la práctica concertada o conscientemente paralela entre licitadores para restringir o falsear la competencia y distorsionar las relaciones entre contratistas y subcontratistas.

\section{BIBLIOGRAFÍA}

Agencia Europea de Defensa: Pasado, Presente Y Futuro. CESEDEN n $107 \mathrm{M}$. de Defensa Madrid 2009 contiene, entre otras, las aportaciones de Alfonso Mairiño, A. "El mercado de la Defensa y el Fortalecimiento de la base tecnológica e industrial de la Defensa europea” (Págs. 181-212) y de Yustos Cordobes “La AED y participación de la industria española (Págs. 213-254)".

Aguado, J. Cudula "Derecho a la Seguridad Pública y Privada" 2007.

Álvarez Conde, E. "El Temor del Príncipe o El Temor al Príncipe” en Anuario Jurídico de La Rioja, nº 31997 Pág. 349-364.

Barcelona Llop, J “El Régimen jurídico de la Policía de Seguridad” IVAP Oñati 1988.

Fernández Segado, F. “Las Fuerzas Armadas y Cuerpos de Seguridad págs. 425 a 523 en Comentarios a la Constitución Española de 1987 Edursa. Madrid 1997.

Edel, F. “'La Convention du Conseil de l' Europe sur l' acces aun docuemnents publics: premier traite consacrant un droit general d' acces aux documents administratifs pags. 59-78. en Revue Française d’ Administration Publique nº $137-1382011$.

Fuertes López, M. “El contratista y el subcontratista ante las Administraciones publicas. M. Pons 1997 y “La deficiente regulación de la Subcontratación en los Contratos de Las Aministraciones Públicas” REDA nº 109 enero-marzo 2001.

García de Herrera Fernández, J. "Estudio de la Subcontratación en la Administración> El Consultor de los Ayuntamientos n 19. 2010 págs. 2825-2835.

Gonzalez Botija. F. "Distribución de competencias entre Estado y Comunidades Autónomas a la luz de los conceptos de Seguridad pública y Policía contenidos en el art. 149.1.29 CE. Comentario a la Sentencia del Tribunal Constitucional 235/2001 de 13 de diciembre REDA Civitas $n^{\circ} 114$, abril- junio 2002.

Gosalbez Pequeño, H. “El Contratista de la Administración Pública. M. Pons 2000.

López Ramón, F. “La caracterización jurídica de las Fuerzas Armadas” CEC 1987.

Mestre Deldado, J. F. “El Derecho de Acceso a Archivos y Registros Administrativos. Análisis del art. 105, b) de la Constitución (ed. Civitas 1998).

Peñarrubia Iza, J.Ma " "El Derecho de Acceso a los Archivos y a los Documentos de la Administración Militar" Cuadernos Civitas. Madrid 1999.

Melero Alonso, E. "El secreto oficial en las ventas de armas. Un supuesto de aplicación ilegal de la Ley sobre Secretos Oficiales (Las razones por las que los datos de las exportaciones Derbent hacerse públicos" RAP $n^{\circ} 52$ mayo-agosto 2000 
Pomed Sánchez, L.A. “EL Acceso a los Archivos administrativos. El marco jurídico y la Practica administrativa” R.A.P n 142. 1997 págs. 439 y ss.

Ponce Sole, J. "Procedimiento Administrativo, Globalización y Buena Administración" en Derecho Administrativo Global, Organización, procedimiento, control judicar (Coor J. Ponce Sole) INAP-MP 2010 págs. 79-101; y “Deber de Buena Administración y Derecho al Procedimiento Debido” L. Nova 2001.

Rams Ramos “El Derecho al Acceso a Archivos y Registros Administrativos”, Madrid 2008.

Rivero Ortega, R. "El Expediente Administrativo. De los Legajos a los Soportes Electrónicos”. Aranzadi $2^{\circ}$ Ed. Aranzadi 2008, págs. 118-131

Sainz Moreno, F. "Secreto e Información en el Derecho Publico" págs. 2863-2981 en Estudios sobre la Constitución Española. Homenaje al Prof. E. García de Enterría Vol. III, Civitas 1991.

Uría Fernández, F. "Procedimientos de contratación en los sectores excluidos (agua, energía, transportes y servicios postales) y Derecho de la Competencia. Análisis del art. 91 de la Ley 31/2007 de 30 de octubre, en Noticias de la Unión Europea nº 301, febrero 2010, págs. 95 a 115. 
